\title{
Electrodialysis potential for fractionation of multicomponent aqueous solutions
}

\author{
Martyna Grzegorzek ${ }^{1, *}$, and Katarzyna Majewska-Nowak ${ }^{1}$ \\ ${ }^{1}$ Wrocław University of Science and Technology, Department of Environmental Engineering, \\ Wybrzeże Stanisława Wyspiańskiego 27, 50-370 Wrocław, Poland
}

\begin{abstract}
The paper aimed at the evaluation of the batch electrodialysis (ED) run in the course of treatment and desalination of various aqueous mixtures containing both mineral (sodium fluoride, sodium chloride) and organic substances (dyes or humic acids). The commercial ED stack (PCCell Bed) equipped with standard anion-exchange and cation-exchange membranes or monovalent selective anion-exchange membranes was used. The ED experiments were performed at a constant current density (1.56 or $1.72 \mathrm{~mA} / \mathrm{cm}^{2}$ ). The mechanism of ion migration as well as membrane deposition for variable solution composition and various membrane types was analyzed The calculated mass balance and electrical energy demand for each ED run were helpful in evaluating the membrane fouling intensity. It was found that the presence of organic substances in the treated solution had a minor impact on energy consumption, but rather strongly affected chloride flux. The extent of organics deposition was significantly lower for monovalent selective anion-exchange membranes than for classic anionexchange membranes.
\end{abstract}

\section{Introduction}

Membrane technology is being increasingly used in the treatment of natural water as well as industry wastewater. Most of the currently conducted studies are focussed on water reuse and reducing pollution impact on the environment. Among membrane processes, the electrodialysis (ED) seems to be very viable technology for simple treatment and desalination of polluted natural and process water. However, electromembrane processes offer also a great opportunity to the recovery of valuable substances, separate charged components from neutral substances, and fractionation of mono- and multi-valence ions of the same sign. These unique advantages make the electrodialysis very attractive in view of environmental and economic benefits. On the other hand, the mechanism of mass transport through the specially designed ion-exchange membranes becomes more complex than through the classic ion-exchange membranes, especially when multicomponent solutions are treated by ED.

Membrane fouling is one of the key obstacles for ensuring cost-efficient operation of membrane systems. In the course of electromembrane processes, the anion-exchange

\footnotetext{
*Corresponding author: martyna.grzegorzek@pwr.edu.pl
} 
membranes are especially prone to fouling by negative charged organics. As a result of this phenomena electrical resistance of the ED stack and power consumption increase.

Among many organic contaminants present in natural and industrial waters, the most studied as potential foulants are: methylamine [1], natural organic matter (NOM) [2-4], surfactants [5, 6], pestides [7], and dyes [8]. The mechanism of organic ion transport trough the anion-exchange membranes is as yet uncertain. Zhang at el. [1] studied the ED process of salt solutions containing various organics of ionic type, which varied in molecular weights. They found that the greater the molecular weight of organic particles the better their retention in diluate cells. Application of monovalent selective anion-exchange membranes resulted in improving of organics separation from mineral components. Similar results were found by Kabsch-Korbutowicz et al. [9] - the ED process with monoselective anion-exchange membranes enabled better regeneration of spent brines contaminated by NOM, than standard ED. Detailed investigation of electrodialytic fractionation of small organic ions from mineral salts revealed that the process efficiency was influenced by current density, organic ion size and charge, as well as by the type of functional groups fixed to organic particles [10]. It is interesting to note that the big organic ions (of molecular weight above $130 \mathrm{kDa}$ ) can be deposited at the membrane surface, thus creating an additional bipolar layer and alternating the membrane selectivity.

Contrary to popular opinion, surfactants can also caused a serious fouling of the anionexchange membranes. Lee et al. [5] found that sodium dodecyl benzene sulfonate (SDBS) generated intensive surface fouling when its concentration was higher than the critical micelle concentration. However, single SDBS particles were able to migrate into membrane structure, thus increasing the electrical resistance and hydrophobicity of the anion-exchange membranes. Analyzing the fouling phenomena in electromembrane processes, the interactions between solutes should also be taken into account. Banasiak et al. [7] proved that the presence of humic acids (HA) in the solution treated by ED reduced deposition of endosulfan (pesticide) at the ion-exchange membranes due to competitive sorption.

The paper aimed at the evaluation of the ED process run during treatment and desalination of various aqueous mixtures containing both mineral (sodium fluoride, sodium chloride) and organic substances (dyes or humic acids).

\section{Methods and materials}

\subsection{Membranes and electrodialysis equipment}

In the experiments on the desalination of organics-salt mixtures the laboratory electrodialytic installation PC Cell Bed-1-System was used. The ED stack (PCCell 64002 model) consisted of 10 cell pairs, thus 10 anion-exchange membranes (standard PC-SA, PCA GmbH, Germany or monovalent selective ACS Neosepta, Tokuyama Soda, Japan) and 11 cation-exchange membranes (standard PC-SK, PCA GmbH, Germany or standard CMV Selemion Asahi Glass, Japan) were applied. Each membrane had an effective surface area of $64 \mathrm{~cm}^{2}$.

The ED system operated in a batch mode, i.e. both diluate and concentrate circulated in the stack till the end of desalination process. The electrode solution tank had a volume of $9 \mathrm{dm}^{3}$ and was filled with $\mathrm{NaCl}$ solution $\left(0.05 \mathrm{~mol} / \mathrm{dm}^{3}\right)$, whereas volumes of the external concentrate and diluate tanks amounted to $2 \mathrm{dm}^{3}$ (each). Flow rate of diluate and concentrate was maintained at $90 \mathrm{dm}^{3} / \mathrm{h}$, giving liquid flow velocity of $6.25 \mathrm{~cm} / \mathrm{s}$ in the electrodialyzer. The maximum value of current intensity which can be obtained with the use of this installation was equal to $5 \mathrm{~A}$. 


\subsection{Reagents}

Model solutions containing organic compounds and mineral salts were used during the ED experiments. They were prepared based on distilled water. Anionic organic dyes varying in molecular weight were chosen as example of anthropogenic contaminants (Merck, Zachem) (Table 1). Dye concentration amounted to $10 \mathrm{mg} / \mathrm{dm}^{3}$. Synthetic solutions containing natural organic matter (NOM) were prepared by dissolving humic acids (HA, Aldrich) at dosages of 5,10 and $15 \mathrm{mg} / \mathrm{dm}^{3}$.

All experimental solutions contained mineral salt - sodium chloride $(\mathrm{NaCl})$ at concentration of $1 \mathrm{~g} \mathrm{NaCl} / \mathrm{dm}^{3}$. Besides, NOM solutions were supplemented with sodium fluoride $(\mathrm{NaF})$. Concentration of fluoride ions in the tested solutions amounted to 5, 10, $100,200 \mathrm{mg} \mathrm{F}^{-} / \mathrm{dm}^{3}$.

Table 2. Characteristics of the experimental dyes.

\begin{tabular}{|c|c|c|c|c|c|c|c|}
\hline Parameter & $\begin{array}{c}\text { Methyl } \\
\text { Orange }\end{array}$ & $\begin{array}{c}\text { Indigo } \\
\text { Carmine }\end{array}$ & $\begin{array}{c}\text { Amido } \\
\text { Black }\end{array}$ & $\begin{array}{c}\text { Titan } \\
\text { Yellow }\end{array}$ & $\begin{array}{c}\text { Direct } \\
\text { Green }\end{array}$ & $\begin{array}{c}\text { Direct } \\
\text { Blue }\end{array}$ & $\begin{array}{c}\text { Direct } \\
\text { Black }\end{array}$ \\
\hline Symbol & MO & IC & AB & TY & DG & DB & DB \\
\hline$\lambda_{\max }, \mathrm{nm}$ & 465 & 610 & 618 & 399 & 370 & 577 & 585 \\
\hline $\begin{array}{c}\text { Molecular } \\
\text { weight, Da }\end{array}$ & 327 & 466 & 615 & 696 & 878 & 1029 & 1084 \\
\hline LogK $_{\text {ow }}{ }^{1}$ & 3.29 & 1.53 & 3.37 & 4.75 & - & - & 5.04 \\
\hline
\end{tabular}

${ }^{1}$ calculated with the use of VCCLAB (http://www.vcclab.org)

\subsection{Methodology}

The electrodialysis desalination process was carried out for water salt solution and model salt solution containing organic contaminants. Generally, the electrodialysis was focused on salt separation from organics, thus at the process beginning the diluate and concentrate chambers contained solutions varied in composition - concentrate tank contained only $\mathrm{NaCl}$ solution $\left(1 \mathrm{~g} / \mathrm{dm}^{3}\right)$, whereas diluate tank contained various solutions: (1) sodium chloride $\left(\mathrm{NaCl}, 1 \mathrm{~g} / \mathrm{dm}^{3}\right)$; (2) mixture of mineral salts $\left(\mathrm{NaF}, 5-200 \mathrm{mg} \mathrm{F} / \mathrm{dm}^{3}\right.$ and $\mathrm{NaCl}$, $\left.1 \mathrm{~g} / \mathrm{dm}^{3}\right)$; (3) mixture of dye $\left(10 \mathrm{mg} / \mathrm{dm}^{3}\right)$ and $\mathrm{NaCl}\left(1 \mathrm{~g} / \mathrm{dm}^{3}\right)$; (4) mixture of HA $\left(5-15 \mathrm{mg} / \mathrm{dm}^{3}\right)$ and salts $\left(\mathrm{NaF}, 5-200 \mathrm{mg} \mathrm{F}^{-} / \mathrm{dm}^{3}\right.$ and $\left.\mathrm{NaCl}, 1 \mathrm{~g} / \mathrm{dm}^{3}\right)$.

The ED experiments were performed a constant current density $\left(1.56 \mathrm{~mA} / \mathrm{cm}^{2}\right.$ for dye solutions and $1.76 \mathrm{~mA} / \mathrm{cm}^{2}$ for HA solutions). The process was terminated when the maximum voltage value was reached (i.e. $24.4 \mathrm{~V}$ ). The determined limiting current density (for initial salt concentration of $1 \mathrm{~g} / \mathrm{dm}^{3}$ ), assuming 90 and $95 \%$ desalination efficiency was equal to 3.27 and $1.64 \mathrm{~mA} / \mathrm{cm}^{2}$, respectively.

In the course of ED process both diluate and concentrate samples were collected every 5-10 minutes and analyzed for organic compound concentration, as well as chloride and fluoride content. For quick evaluation of desalination efficiency the electrolytic conductivity was measured.

The dye concentration was determined spectrophotometrically at the wavelengths $\left(\lambda_{\max }\right)$ listed in Table 1, which corresponded to the maximum absorbance of the sample. The humic acids (HA) content was also detected spectrophotometrically at the UV wavelength of $254 \mathrm{~nm}$. The spectrophotometer Hitachi U-1900 was used for absorbance measurements. The fluoride content was determined by a colorimetric analysis with SPADNS reagent (at the wavelength of $580 \mathrm{~nm})$. The spectrophotometer DR $2000(\mathrm{HACH})$ was applied for fluoride ion analysis. Concentration of chloride ions in salt solutions was determined by 
Mohr method (PN-ISO 9297:1994). The electrical conductivity was monitored with the use of conductometer Elmetron CC-41.

The anion flux through the membranes was calculated according to the following equation:

$$
J=\frac{V_{t} C_{t}-V_{i} C_{i}}{A_{m} t}
$$

where: $J$ - ion flux $\left(\mathrm{mol} / \mathrm{m}^{2} \mathrm{~h}\right), A_{m}$ - total surface area of the anion-exchange membranes $\left(\mathrm{m}^{2}\right), V_{i}, V_{t}$ - volume of the concentrate at the beginning of the process and at a time $t$, respectively $\left(\mathrm{m}^{3}\right), C_{i}, C_{t}$ - anion concentration at the beginning of the process and at a time $t$ in the concentrate cells, respectively $\left(\mathrm{mol} / \mathrm{m}^{3}\right), t$ - process duration (h).

The amount of organics deposited in the ED/membrane system was calculated by using a mass balance according to the following equation:

$$
M=\left(V_{i d} C_{i d}+V_{i c} C_{i c}\right)-\left(V_{f d} C_{f d}+V_{f c} C_{f c}\right)
$$

where: $M$ - mass of dyes or HA accumulated in the ion-exchange membranes $(\mathrm{mg}), V_{i d}, V_{f d}$ - initial and final volume of diluate $\left(\mathrm{m}^{3}\right), V_{i c}, V_{f c}$ - initial and final volume of concentrate $\left(\mathrm{m}^{3}\right), C_{i d}, C_{f d}$ - initial and final concentration of dyes or HA in the diluate $\left(\mathrm{mg} / \mathrm{dm}^{3}\right), C_{i c}$, $C_{f_{c}}$ - initial and final concentration of dyes or HA in the concentrate $\left(\mathrm{mg} / \mathrm{dm}^{3}\right)$.

Changes of voltage were monitored for each ED run and the electrical energy demand was calculated according to the method given in [11].

\section{Results}

\subsection{ED run under the presence of humic acids}

Generally, the ED of fluoride solutions (containing HA) resulted in $88-91 \%$ of $\mathrm{F}^{-}$ions removal and in $90-97 \%$ desalination efficiency (detailed data not shown). The variation of the mean chloride flux in relation to various composition of treated solution is given in Fig.1. The results obtained show significant influence of humic acids as well as increasing concentration of fluoride ions on chloride transport through the standard ion-exchange membranes. The chloride flux decreased from $780 \mathrm{mmol} / \mathrm{m}^{2} \mathrm{~h}$ for solution containing only $\mathrm{Cl}^{-}$and low amount of $\mathrm{F}^{-}$ions $\left(5 \mathrm{mg} \mathrm{F} / \mathrm{dm}^{3}\right)$ to $330 \mathrm{mmol} / \mathrm{m}^{2} \mathrm{~h}$ for solution supplemented with humic acids $\left(5 \mathrm{mg} \mathrm{HA} / \mathrm{dm}^{3}\right)$ and high concentration of $\mathrm{F}^{-}$ions $\left(200 \mathrm{mg} \mathrm{F}^{-} / \mathrm{dm}^{3}\right)$.

It seems that the effect of increasing content of fluoride on chloride migration through the anion exchange membranes is much greater than the presence of organic matter. This relation becomes clear by keeping in mind that all experiments were performed at the constant current density and constant chloride concentration. Thus, increasing fluoride concentration simply results in the increase of total dissolve solids and decreasing desalination rate.

The addition of HA into desalted solution brought about considerable worsening of $\mathrm{Cl}^{-}$ion flux. This drop in ion flux was approximately constant, irrespectively of the HA concentration. This observation seems to be in a some contradiction with the results shown in Fig. 3, where masses of accumulated HA are given. The amount of deposited NOM was proportional to the HA initial concentration, however this phenomena was not reflected in a significant deterioration of $\mathrm{Cl}^{-}$ion flux. On the other hand, a slight worsening of the mean fluoride ion flux with increasing HA content can be detected (Fig. 2). Generally, the mean $\mathrm{F}^{-}$ion flux was proportional to the initial $\mathrm{F}^{-}$content and varied from 5.7 to $215 \mathrm{mmol} / \mathrm{m}^{2} \mathrm{~h}$. 
It was higher for solutions containing mineral salts only in comparison to solutions with HA content.

It appears that the observed relationships can be explained by considering the mobility and radius of ions present in model solutions. The ionic mobility of $\mathrm{Cl}^{-}$and $\mathrm{F}^{-}$ions is equal to 7.92 and $5.70 \mathrm{~m}^{2} / \mathrm{Vs}$, respectively [3], whereas their hydrated radiuses amount to 0.332 and $0.352 \mathrm{~nm}$. Thus, $\mathrm{Cl}^{-}$ions are more preferably transported than $\mathrm{F}^{-}$ions under the presence of organic membrane foulant.

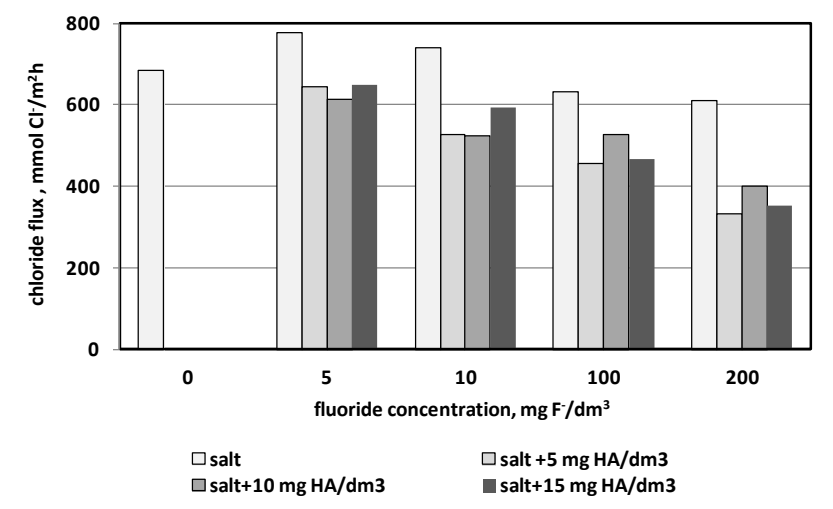

Fig. 1. Chloride flux versus fluoride and humic acids (HA) concentration (salt $-1 \mathrm{~g} \mathrm{NaCl} / \mathrm{dm}^{3}$, current density $-1.72 \mathrm{~mA} / \mathrm{cm}^{2}$ ).

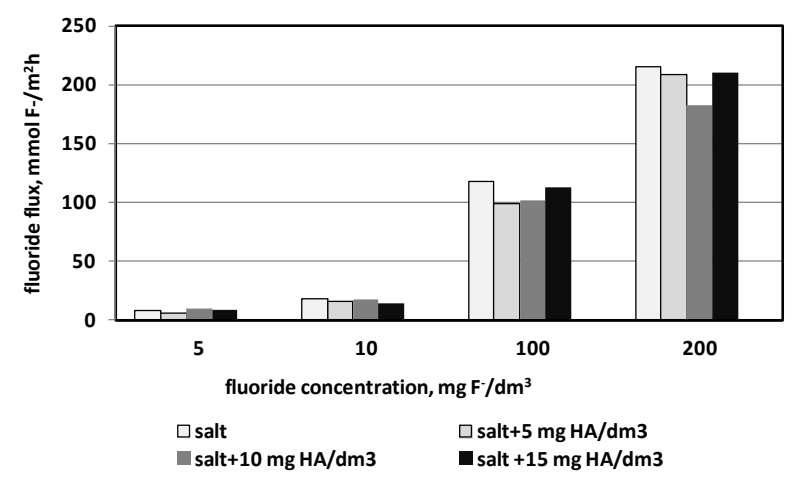

Fig. 2. Fluoride flux versus humic acids (HA) concentration (salt $-1 \mathrm{~g} \mathrm{NaCl} / \mathrm{dm}^{3}$, current density $1.72 \mathrm{~mA} / \mathrm{cm}^{2}$ ).

\subsection{ED run under the presence of organic dyes}

The ED experiments of organic dye-salt mixtures revealed excellent desalination efficiency, however the concentrate streams were less contaminated by dyes when monovalent selective anion-exchange membranes were used (detailed data not shown).

The variation of mean chloride flux during the ED desalination of dye solutions is shown in Fig. 4. In this stage of experiments the ED process was performed with the use of standard as well as monovalent selective anion-exchange membranes. Basically, the $\mathrm{Cl}^{-}$ion flux varied in a small extent - from 480 to $590 \mathrm{mmol} / \mathrm{m}^{2} \mathrm{~h}$ (with the exception of MO 
solution). The differences between chloride fluxes for standard and monoselective anionexchange membranes were not remarkable, however some relations can be inferred.

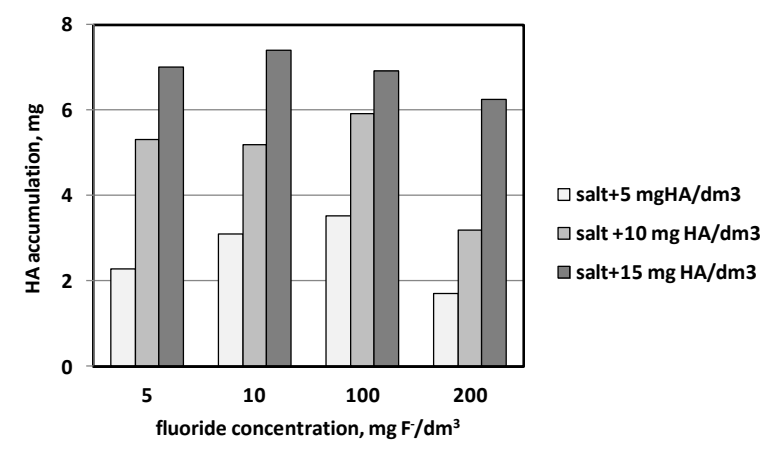

Fig. 3. Amount of humic acids (HA) accumulated in membranes versus fluoride and HA concentration (salt $-1 \mathrm{~g} \mathrm{NaCl} / \mathrm{dm}^{3}$, current density $-1.72 \mathrm{~mA} / \mathrm{cm}^{2}$ ).

In principle, the monovalent selective anion-exchange membranes were characterized by a slight lower chloride flux than standard membranes when chloride solution was treated. This seems quite obvious due to additional negative-charged layer at the membrane surface, which increases membrane electrical resistance.

Comparing the membrane performance in view of chloride removal from dye solutions, it can be concluded that in most cases the $\mathrm{Cl}^{-}$flux was higher for monovalent selective anion-exchange membranes than for standard membranes. However, for DG and TY solutions this observation was not so evident.

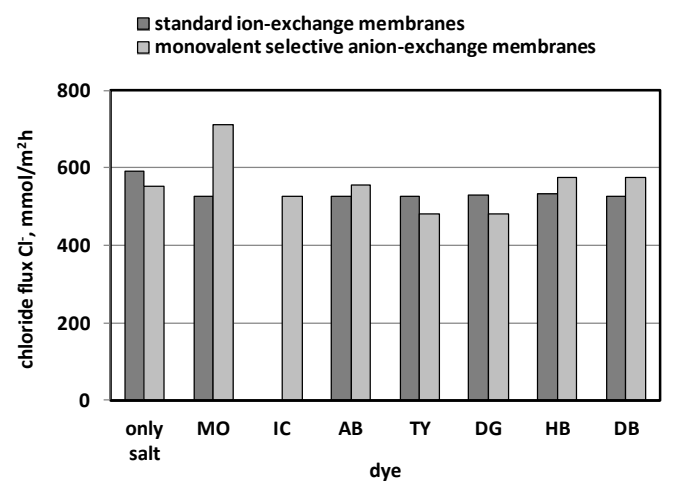

Fig. 4. Chloride flux in the course of ED desalination of model solutions containing various organic dyes (dye concentration $-10 \mathrm{mg} / \mathrm{dm}^{3}$; current density $-1.56 \mathrm{~mA} / \mathrm{cm}^{2}$ ).

Dyes are known as organic substances of hydrophobic nature (Table 1) and great fouling potential. This is reflected in Fig. 5, which shows the extend of dye accumulation in the anion-exchange membranes. The membrane fouling caused by dyes was very intensive in relation to standard membranes. It is interesting to note that the extent of dye adsorption was influenced mainly by their molecular weights - the lower the molecular weight, the greater the dye mass deposited on membrane. This observation suggests facilitated penetration of small dye particles into membrane matrix. The application of mono-selective 
anion-exchange membranes resulted in almost complete elimination of dye adsorption and improvement of chloride flux.

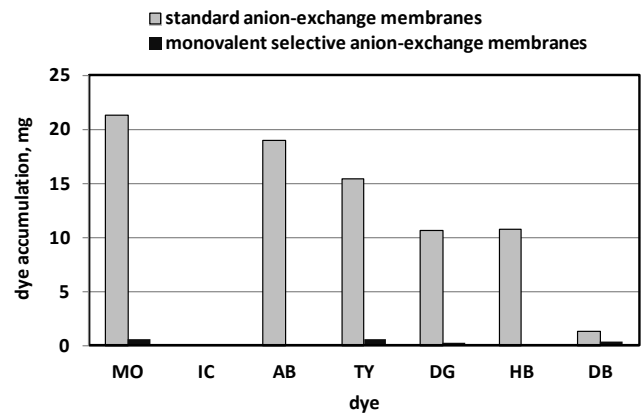

Fig. 5. Amount of dyes accumulated in membranes in the course of ED desalination of dye solutions (dye concentration $-10 \mathrm{mg} / \mathrm{dm}^{3}$; current density $-1.56 \mathrm{~mA} / \mathrm{cm}^{2}$ ).

\subsection{Electrical energy demand}

Generally, the energy consumption is an essential factor in practical applications. On the other hand, it can be a measure of the correctness of the ED process run. The calculated energy consumption for dye and fluoride solutions is given in Table 3 and Fig. 6, respectively.

Table 3. Energy consumption (EC) for ED desalination of dye-salt mixtures (salt $-1 \mathrm{~g} \mathrm{NaCl} / \mathrm{dm}^{3}$, current density $-1.56 \mathrm{~mA} / \mathrm{cm}^{2}$ ).

\begin{tabular}{|l|l|l|l|l|l|l|l|l|}
\hline Dye symbol & MO & IC & AB & TY & DG & HB & DB & H$_{2} \mathbf{O}$ \\
\hline \multicolumn{8}{|c|}{ Standard anion-exchange membrane PC-SA } \\
\hline $\mathrm{EC}, \mathrm{kWh} / \mathrm{m}^{3}$ & 0.25 & - & 0.37 & 0.46 & 0.39 & 0.40 & 0.41 & 0.27 \\
\hline \multicolumn{7}{|c|}{ Monovalent selective anion-exchange membrane (ACS) } \\
\hline $\mathrm{EC}, \mathrm{kWh} / \mathrm{m}^{3}$ & 0.38 & 0.40 & 0.49 & 0.55 & 0.48 & 0.48 & 0.49 & 0.47 \\
\hline
\end{tabular}

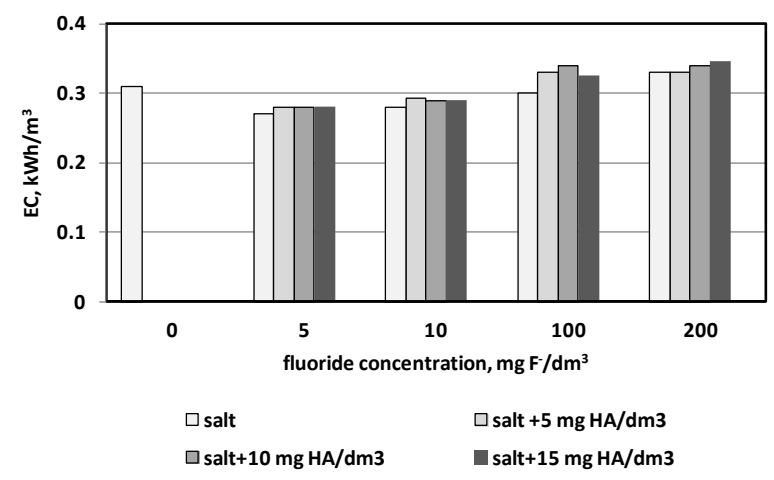

Fig. 6. Energy consumption (EC) versus fluoride and humic acids (HA) concentration (salt $-1 \mathrm{~g} \mathrm{NaCl} / \mathrm{dm}^{3}$, current density $-1.72 \mathrm{~mA} / \mathrm{cm}^{2}$ ). 
From the results obtained (Table 3 ) in can be inferred that the power consumption is almost of the same value, irrespectively of the type of organic dye. However, a slight shift towards higher power demand was observed with the increasing of dye molecular weight. This observation is valid for both anion-exchange membranes used. It is interesting to note that the ED process with monovalent selective anion-exchange membranes exhibited higher energy consumption than ED with standard anion-exchange membranes. This can be attributed to the higher electrical resistance and denser structure of ACS membranes than PC-SA membranes.

Unexpectedly, it can be concluded that humic acids slightly increased the energy demand in the course of ED process with fluoride solutions (Fig. 6). Although the HA deposition at/in membranes was confirmed (Fig. 2), the variation in energy used with increasing HA content was less than $10 \%$. Fluoride concentration was the main factor which influenced the energy demand in the case of fluoride solutions. This finding seems to be clear when Faraday law is taken into account.

\section{Conclusions}

1. The presence of humic acids (HA) in the salt solutions treated by electrodialysis caused a considerable worsening of chloride flux, irrespectively of HA concentration. The fluoride flux decreased with the increasing HA content. The drop of $\mathrm{F}^{-}$ion flux was especially significant when HA concentration amounted to $10 \mathrm{mg} / \mathrm{dm}^{3}$.

2. Although the HA deposition in the ion-exchange membranes was confirmed, the increase in the electrical energy demand with increasing HA content was less than $10 \%$.

3. The use of monovalent selective anion-exchange membranes resulted in almost complete elimination of dye deposition and improvement of chloride flux.

The financial support of the Faculty of Environmental Engineering (Wroclaw University of Science and Technology, grant no. 0402/0080/16) is greatly appreciated.

\section{References}

1. Y. Zhang, B. Van der Bruggen, L. Pinoy, B. Meesschaert, J. Membrane Sci. 332, 104 (2009)

2. H.J. Lee, D.H. Kim, J. Cho, S.H. Moon, Desalination 151, 43 (2002)

3. L.J. Banasiak, A.I. Schäfer, J. Membrane Sci. 334, 101 (2009)

4. H.J. Lee, S.H. Moon, S.P. Tsai, Sep. Purif. Technol. 27, 89 (2002)

5. H.J. Lee, M.K. Hong, S.D. Han, J. Shim, S.H. Moon, J. Membrane Sci. 325, 719 (2008)

6. V. Lindstrand, G. Sundström, A. Jönsson, Desalination 128, 91 (2000)

7. L.J Banasiak, B. Van der Bruggen, A.I. Schäfer, Chem. Eng. J. 166, 233 (2011)

8. S. Caprarescu, A.R.Miron, V. Purcar, A.L. Radu, A. Sarbu, D. Ion-Ebrasu, L.I. Atanase, M. Ghiurea, Water Sci. Technol. 74, 2462 (2016)

9. K. Kabsch-Korbutowicz, J. Wisniewski, S. Kliber, A. Urbanowska, Desalination 280, 428 (2011)

10. Y. Zhang, L. Pinoy, B. Meesschaert, B. Van der Bruggen, AIChE J. 57, 2070 (2011)

11. R. Rautenbach, Membrane processes (Wiley, 1989) 